\title{
Some Theoretical and Practical Problems Facing Chinese International Education
}

\author{
Liang Yu
}

International cultural exchange college, XinJiang University Wulumuqi XinJiang, 830046, China.

Keywords: Chinese international education; teaching problems; theory and practice.

\begin{abstract}
Chinese reform and opening up has made its social economy have great progress, and China has increasing influence around the world along with the rapid growth of economy and national strength. Besides, China has got more economic trade and cultural communication with other countries. So it is of great necessity to develop intention education to better realize economic trade and cultural exchange, which is also an inevitable trend. However, due to its short development period in the practical teaching, Chinese international education still belongs to new major and it is faced with various problems to be solved in its professional development, including theoretical and practical problems.
\end{abstract}

\section{Introduction}

Chinese is used to exchange with outside world, which is the belt to make economic trade and cultural communication with other countries. Along with the enhancing of national power and Chinese influence, it is one of the subjects to be solved in the current language education that how to effectively communicate Chinese around the world. In recent years, Chinese international education system has been gradually sound through constant improvement to better satisfy the learning demand with Chinese of foreigners from different countries. Chinese international education courses have tended to be professional, and teaching courses have made great progress. Theory is closed with practice in Chinese teaching. And the combination of them is the effective method to learn Chinese. But in the current Chinese international education, it is a prominent problem that theory is deviated from practice, and teaching effects are difficult to guarantee due to lacking of good combination.

\section{System of Chinese International Education}

\subsection{Disciplinary Study of Chinese International Education}

Current Chinese international education has made great process and teaching contents are more diversified. It mainly includes the foreign Chinese teaching and overseas Chinese teaching. It can be seen from Chinese condition that many overseas students have actively started to learn Chinese and the number is gradually increasing. And it can be seen from the global condition that the number of learning Chinese aboard is constantly increasing, which shows the influence of Chinese international education. Therefore it also pushes the teaching research of Chinese international education. However, from the perspective of teaching research development condition of current Chinese international education, the disciplinary study of foreign Chinese teaching is better than overseas Chinese teaching. It manifests that the teaching research level is deeper and the latter one lacks the suited teaching research, academic value and theoretical research of teaching meaning. It can be found from the current status of disciplinary study that persons occupied in international Chinese teaching mainly be based on domestic Chinese teaching and lack teaching experience on the overseas Chinese teaching. And they have no opportunity to deeply understand the international Chinese teaching, so there exists the weak theoretic research in current foreign Chinese teaching.

\subsection{System Construction of Chinese International Education}

Nowadays, most countries pay special attention to the learning of the second language and Chinese has been listed the second language by many countries along with the increasing strengthening of Chinese national power and international influence. However, it must be admitted 
that lacking of practical teaching system for Chinese international teaching has led to its lack of development objects, despite Chinese increasing influence in the world. So the teaching is under the groping, with will have some negative effects on the disciplinary development of Chinese International education. Thus, in order to push its development, the related theoretical research should bd solved and the disciplinary system good for its development should be constructed through the implementation with teaching theory research. So its original development mode in practical teaching should be transformed to connect with the world, and we should fully realize that international Chinese teaching is different from other disciplinary teaching, and it is kind of particular. Only by this way can the related theoretical research be more valuable and theoretical system be more of Chinese characteristics.

\section{Theoretical and Practical Problems Needing to be Solved in Chinese International Education}

\subsection{The Theory Teaching of Chinese International Education is Rather Behind}

Theoretical teaching plays a significant role in Chinese teaching, but the current theoretical teaching needs to be improved. In Chinese teaching, some teachers adopt rather single teaching model and the teaching content is just limited in the textbook, so Chinese international theoretical teaching will make students bored and dull, which causes that many students are not interested in theoretical learning. Besides, the teaching of part teachers lacks the creativity. Their class teaching still adopts original teaching methods, namely, teachers focus on the pure explanation of theories and students' learning lacks positiveness. So students are passive to accept theoretical knowledge and teachers cannot play a leading role in the class teaching. There is no communication and discussion between teachers and students, which will result in that students are hard to comprehensively understand and absurd the knowledge although such method has systematical and direct advantages for knowledge imparting. Students' abilities to change knowledge to ability will be confined, which will affect their positiveness and initiative to some extent.

\subsection{Combination Problem Between Chinese International Education Theory and Practical Teaching}

There also exists the disjoint phenomenon between theoretical teaching and practical teaching in the teaching practice of Chinese international education. Due to the failure of integration, students' ability to understand Chinese knowledge will be affected and the teaching effect cannot be guaranteed. For example, some teachers put more efforts into the teaching of theoretical knowledge in their practical teaching, having one-sided thinking of significant effect of theoretical teaching. The behavior that attaching more importance to the theoretical teaching has affected students' language application ability. In addition, many examinations for Chinese in domestic schools are limited in the written form, while teachers regard how to enhance students' written grade as the teaching emphasis in order to finish their teaching tasks, which is of teaching to test. What's more, teachers cannot connect the practical teaching and theoretical knowledge in the practical teaching, which means that the theoretical knowledge cannot be applied to the specific language, having the formal disadvantage. In the learning process of language, practice is a significant part that can help students better understand their learned theoretical knowledge and is good for enhancing students' spoken Chinese level. However, affected by traditional teaching mode, part schools fail to launch the related practical courses which will influence the whole quality of Chinese international education.

\subsection{Ignorance of Cultural Factors in the Teaching Process}

Language is closely related with culture, and culture is spread through language. Language is the foundation of culture. Different culture can be reflected through specific languages, so various languages express various culture connotation. In the process of learning Chinese, cultural factor is the key one to confine the enhancing of Chinese international education level. Language is closed with culture, so language can reflect distinct cultural connotation. For instance, in Chinese, the representative characteristic is that Chinese can reflect Chinese traditional culture, and it can manifest Chinese philosophical ideology and traditional customs. But current Chinese international teaching 
hasn't realized the significant effect of cultural factors on Chinese learning, so it should be avoid in the teaching that analyzing the existing cultural difference not combining with the practical conditions of students but limited in domestic teaching.

\section{Effective Measures to Promote the Quality of Chinese International Education}

\subsection{Innovate Teaching Methods}

Teachers should pay attention to teaching effects in the teaching practice of Chinese international education, and they should take effective measures to create opportunities to have students participate in teaching. Students can express their feelings in the process of learning language and communicate with each other, which can help them learn from each other and make a progress together. The adoption of cooperative learning teaching mode can strengthen the interactive and communicative effect of the class. The atmosphere can become relaxing and happy through the communication among students. And the teaching mode of mutual help can help those students with weak study abilities directly learn new learning methods to realize the difference with others. While cooperative learning method contributes to enhance students' positive thoughts and strengthen teaching efficiency. And this method can help students improve Chinese qualities in the process of discussing problems together. Teachers' teaching design should combine with the related language environment and it should let students not only master Chinese knowledge but enhance the ability to solve practical problems through the cooperation. And the teamwork among students is also strengthened. As for teachers, they should change their thoughts and realize existing shortcomings in the original teaching and realize the necessity of innovating teaching mode. For instance, the adoption of overturning class for Chinese international education can create harmonious class atmosphere that can effectively enhance students' class learning efficiency and make the class teaching get effective implementation. Various creative teaching modes can be adopted in teaching process, for example, group-teaching can make the class atmosphere active through the communication among group members. In order to achieve the creation of interactive teaching scenes, teachers should strengthen the learning and application of multimedia teaching technology. And the creation of such scene cannot leave the application of advanced multimedia teaching mode. All there informational teaching tools can effectively strengthen students' visual and audio feelings.

\subsection{Focus on the Combination of Theory Teaching and Practical Teaching}

In order to enhance the total level of domestic Chinese international education, teachers should firstly realize the significant effect of combining the theoretical teaching and practical teaching. Teachers should enhance students' expressive abilities through correct guidance to let students have the awareness of actively expressing themselves, which is contributed to enhancing students' confidence. In the process of Chinese teaching, students' expressive abilities manifest from two aspects. The enhancement of students' expressive abilities can enhance their comprehensive qualities. No matter where they are, only the equipment of expressive abilities can realize the communication. Students should have the basic abilities to rein language and characters through language learning. Teachers should improve students' expressive abilities through strengthening their language abilities. And they should be aware of increasing students' language foundation. Students use Chinese theoretical knowledge to realize language communication in the practice and they should have the language thought skills and abilities to speak and express. Listeners also need language thought to understand the content of language. The improvement of expressive abilities also contributes to the correct understanding of expressive contents and inner thoughts. Therefore, the training of students' comprehensive abilities should pay attention to the promotion of students' language expressive abilities. The teaching mode that is oriented with teachers in traditional teaching should be changed in the class teaching, and the start point should be the personal difference of students and teaching contents should be centered with students. Such teaching method varies from the original one, in which teachers will not be the transmitter of knowledge and leader of class teaching but the organizer in the learning process. So teachers should adopt effective teaching mode with the combination of the reality of Chinese international education to fully motivate students' initiative. In addition, teachers 
should take the cultural difference into the practice and master cultural connection. The thorough understanding with cultural connotation is beneficial to the promotion of teaching effects.

\section{Conclusion}

Currently, the whole level of Chinese international education has greatly been promoted. However, there still exist various problems to be solved in teaching practice. And it is necessary to take effective countermeasures to promote the influence of Chinese international education. The workers occupied in Chinese international education should firstly realize the significant effect and characteristics of Chinese international education, focusing on the mutual combination of theoretical and practice in the teaching. Teaching objects should highlight students' comprehensive qualities. On the other hand, teachers should actively explore the teaching methods adapting to Chinese international education and eliminate the existing shortcoming in the original teaching and innovate teaching methods in combination with the characteristic of language teaching to enhance teaching effects.

\section{References}

[1]. Baoping Zhang. Analysis of Practical Teaching System in TCFL [J]. Modern Chinese, 2016(11):104-105.

[2]. Huazhen Li, Zhenwei Sun. Practice and Thinking of the Talents Training Model in TCFL[J]. Journal of Taizhou Institute,2016(9):137-138.

[3]. Zhaoxia Sun. Reform and Discussion on the Talents Training Schemes of TCFL in Local Colleges[J]. Journal of Chifeng Institute,2016(11):87—88.

[4]. Bo Zhang. The Thoughts and Methods Construction of Practice Model in TCFL[J]. Literature (theory),2016(9):121-122.

[5]. Zhendong Zhang. Some Theoretical and Practical Problems Facing Chinese International Education[J]. Jiannan Literature (the latter month),2015(1): 152 - 153.

[6]. Jianguo Hu. Cross-cultural Essence and Theoretical and Practical Meaning of Chinese International Education[J]. Chinese International Communication Research,2015(7): 198 - 199. 